\title{
TITLE:
}

\section{Indirect Immunofluorescence Assay in Chlamydomonas reinhardtii}

AUTHOR(S):

Yamano, Takashi; Fukuzawa, Hideya

CITATION:

Yamano, Takashi ...[et al]. Indirect Immunofluorescence Assay in

Chlamydomonas reinhardtii. bio-protocol 2016, 6(13): e1854.

ISSUE DATE:

2016-07-05

URL:

http://hdl.handle.net/2433/244823

RIGHT:

(C) 2016 The Authors; exclusive licensee Bio-protocol LLC.; 許諾条件に基 づいて掲載しています。 


\title{
Indirect Immunofluorescence Assay in Chlamydomonas reinhardtii
}

Takashi Yamano and Hideya Fukuzawa*

Graduate School of Biostudies, Kyoto University, Kyoto, Japan

*For correspondence: fukuzawa@lif.kyoto-u.ac.jp

\begin{abstract}
[Abstract] Determining the protein localization is essential to elucidate its in vivo function. Fluorescence-tagged proteins are widely used for it, but it is sometimes difficult to express tagged proteins in Chlamydomonas. Alternatively, indirect immunofluorescence assay is also one of the widely used methods and many reports determining the localization of Chlamydomonas proteins using this method are published. Here, we introduce a protocol of indirect immunofluorescence assay adapted from our papers reporting LCIB ( $\mathrm{CO}_{2}$-recycling factor in the vicinity of pyrenoid; Yamano et al., 2010), LCl1 (plasma membrane-localized inorganic carbon transporter; Ohnishi et al., 2010), HLA3 (plasma membrane-localized ABC-type bicarbonate transporter; Yamano et al., 2015), and LCIA (chloroplast envelope anion channel; Yamano et al., 2015) in Chlamydomonas reinhardtii. The protocol described here could be useful for observing the protein of interest in other algae cells.
\end{abstract}

\section{Materials and Reagents}

1. Poly-L-lysine-treated glass slide (Poly-Prep Slides) (Sigma-Aldrich, catalog number: P042572EA)

2. Coverslips (Matsunami Glass, catalog number: C218181)

3. Dako Pen (Dako, catalog number: S2002)

4. Plastic box $(9 \mathrm{~cm} \times 19 \mathrm{~cm} \times 4 \mathrm{~cm})$ Note: In this experiment, but any size is OK.

5. Kimwipes ${ }^{\circledR}$ paper (Kimberly Clark)

6. Chlamydomonas cells of interest

7. Hematocytometer (Erma, catalog number: 03-303-6)

8. Phosphate-buffered Saline (PBS)

9. Tween-20 (Santa Cruz, catalog number: sc-29113)

10. PBS-T (PBS with $0.1 \%$ Tween-20)

11. Paraformaldehyde (Nacalai Tesque, catalog number: 26126-54)

12. Methanol (Nacalai Tesque, catalog number: 21915-64)

13. Globulin-free Bovine Serum Albumin (BSA) (Nacalai Tesque, catalog number: 01281-26)

14. Affinity-purified rabbit primary antibody against LCIB (Yamano et al., 2010)

15. Goat anti-Rabbit IgG $(\mathrm{H}+\mathrm{L})$ Secondary Antibody, Alexa Fluor ${ }^{\circledR} 488$ conjugate (Thermo Fisher, catalog number: A-11001)

16. Mounting medium (Vectorshield, catalog number: $\mathrm{H}-1300$ ) 
17. $4 \%$ formaldehyde (see Recipes)

18. PBS (see Recipes)

19. PBS-T (see Recipes)

20. Blocking solution (see Recipes)

\section{Equipment}

1. Coplin jar (50 ml size)

2. Fluorescence microscopy Axioscope2 (Zeiss) with a specific filter set (excitation bandpass 480/40 and emission band pass 527/30) or laser scanning confocal microscopy TCS SP8 (Leica) with a $488 \mathrm{~nm}$ laser line

Note: these were the instruments used throughout our experiments, but any company is OK.

\section{Procedure}

1. Chill $100 \%$ methanol in a Coplin jar at $-20^{\circ} \mathrm{C}$ for at least $4 \mathrm{~h}$.

2. Harvest $50 \mathrm{ml}$ of Chlamydomonas cells at the log growth phase by centrifugation at $600 \mathrm{xg}$ for $5 \mathrm{~min}$. This and subsequent steps are performed at room temperature except for step 10. Notes:

a. Chlamydomonas culture media recipes are available at http://www.chlamy.org/media.html.

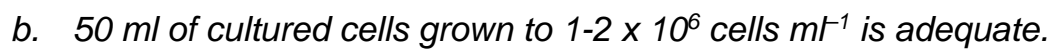

3. Resuspend the cells in small volumes $(1-2 \mathrm{ml})$ of PBS, count the cell number by hematocytometer, and adjust the cell density at $1 \times 10^{7}$ cells $\mathrm{ml}^{-1}$ using PBS.

4. Draw three circles on a Poly-L-lysine-treated glass slide with Dako Pen to provide a barrier to liquids such as blocking solution, antibody solution, and washing buffer (Figure 1A). Dry the circles at room temperature.

5. Put $100 \mu \mathrm{l}$ of Chlamydomonas cell suspension in each circle and let them air-dry for $5 \mathrm{~min}$ to fix the cells to the glass.

Note: If you let them sit longer, more Chlamydomonas cells will adhere, but the ends of the flagella of cells start to curl up.

6. Permeabllize the cells by immersing the glass slide into a Coplin jar filled with PBS-T for 10 min (Figure 1B).

7. Prepare a clean plastic box with a few damp Kimwipes ${ }^{\circledR}$ paper at the bottom to keep the air humid.

8. Place the glass slide on a cap of plastic tube placed in the plastic box (Figure 1C) and fix the proteins within cells by applying $100 \mu \mathrm{l}$ of PBS containing $4 \%(\mathrm{w} / \mathrm{v})$ formaldehyde to the cells for 20 min. Make sure that the solution is within the circles and the entire cells are covered by the PBS solution. 

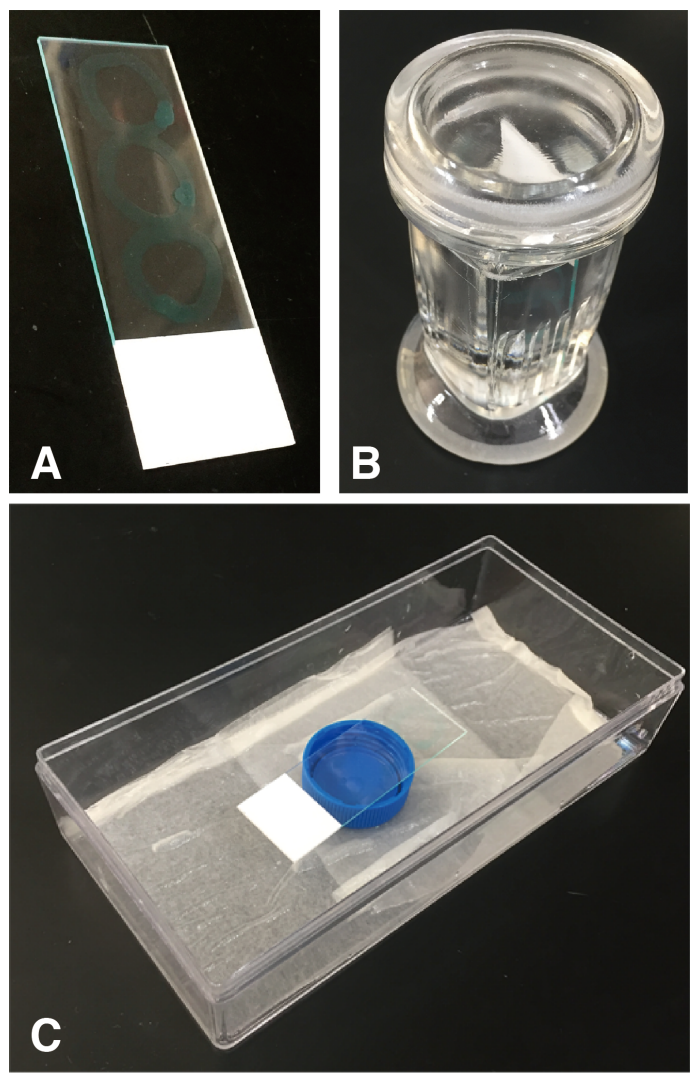

Figure 1. Devices for indirect immunofluorescence assay. A. Example of circles drawn by Dako Pen on a Poly-L-lysine-treated glass slide. B. Immersed glass slide in a Coplin jar filled with PBS-T. C. Humid plastic box with a few damp Kimwipes ${ }^{\circledR}$ papers and a glass slide on a cap of plastic tube.

9. Wash the cells two times by immersing the glass slide into a Coplin jar filled with PBS for 5 min. Note: You do not need to shake the slides or jars during washing.

10. Fix the cells by immersing the glass slide into a Coplin jar filled with pre-chilled $100 \%$ methanol at $-20{ }^{\circ} \mathrm{C}$ for $20 \mathrm{~min}$. Because chlorophyll will be solubilized, the methanol becomes green.

Note: Because the temperature of the chilled methanol is important in the fixation, it is recommended to keep the methanol in a freezer at $-20{ }^{\circ} \mathrm{C}$ overnight before use.

11. Rehydrate the cells by immersing the glass slide into a Coplin jar filled with PBS for 5 min.

12. Pour off the PBS and repeat the rehydration step 11 two times. If you perform time-course experiments, you can let the glass slide sit in PBS for several hours until you are ready.

13. Take out the glass slide from the Coplin jar and let it air-dry for $5 \mathrm{~min}$.

14. Block the cells on the glass slide by applying $100 \mu \mathrm{l}$ of blocking solution for $1 \mathrm{~h}$ in the humid plastic box.

15. Wash the cells two times by immersing the glass slide into a Coplin jar filled with PBS for 5 min. Note: You do not need to shake the slides or jars during washing.

16. Take out the glass slide from the Coplin jar and let it air-dry for 5 min. 
17. Apply $50 \mu \mathrm{l}$ of PBS-T containing the primary antibody at the dilution rate of $1: 500$ and incubate the cells for $1 \mathrm{~h}$ in the humid plastic box.

18. Wash the cells six times by immersing the glass slide into a Coplin jar filled with PBS-T for 5 min.

19. Apply $50 \mu \mathrm{l}$ of PBS-T containing secondary antibody at the dilution rate of 1:500 and incubate the cells for $1 \mathrm{~h}$ in the humid plastic box. Keep in the dark.

20. Wash the cells six times by immersing the glass slide into a Coplin jar filled with PBS-T for 5 $\min$.

21. Apply $15 \mu \mathrm{l}$ of mounting solution to the cells. Make sure that no air bubbles are formed.

22. Cells are now ready for observation by fluorescent microscopy with a specific filter set (excitation bandpass $480 / 40$ and emission bandpass $527 / 30$ ) or laser scanning confocal microscopy with a $488 \mathrm{~nm}$ laser line. Glass slide can be stored for a week at $4{ }^{\circ} \mathrm{C}$ in the dark.
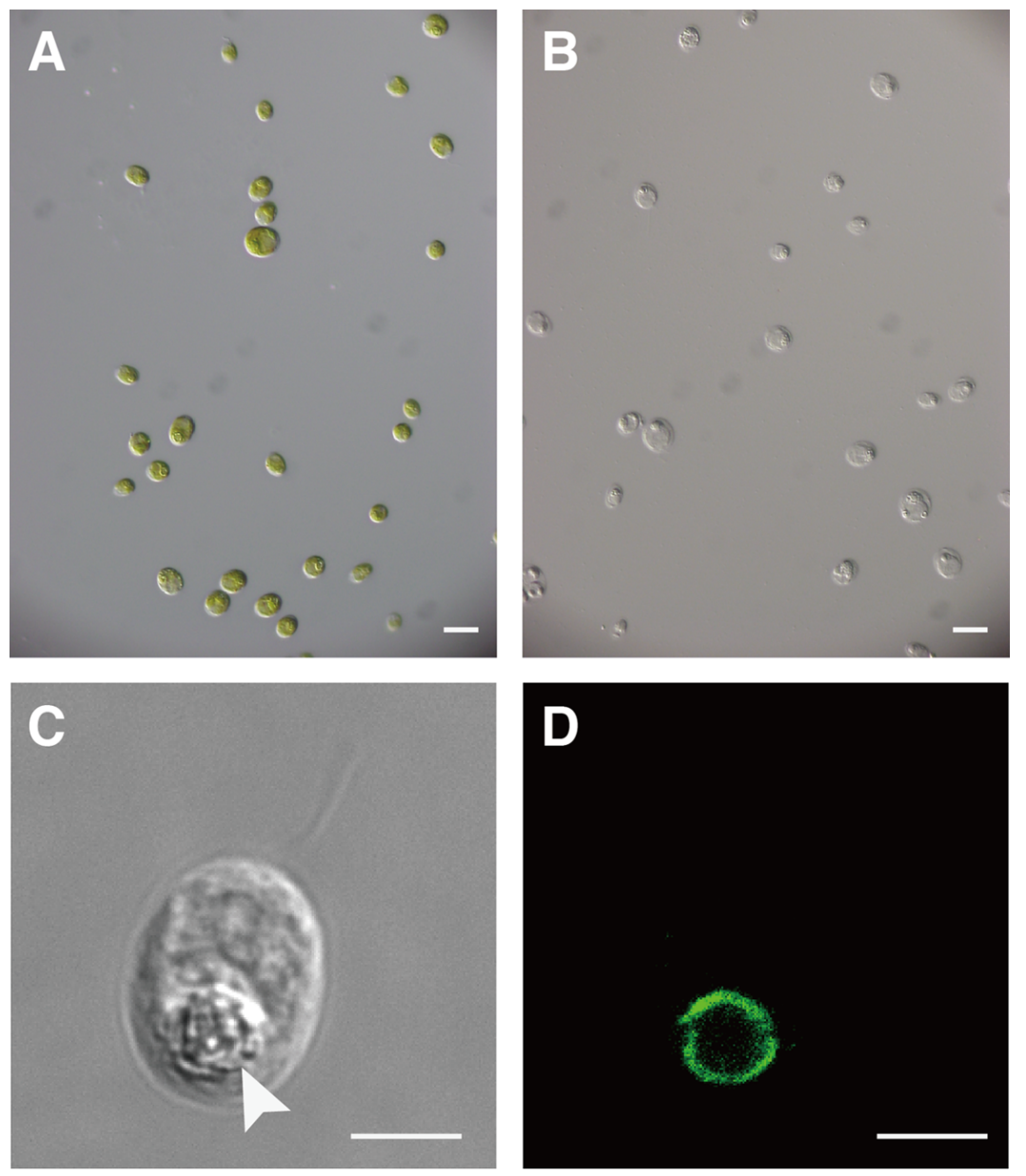

Figure 2. Actual cell images and fluorescence signals of indirect immunofluorescence assay. A. Fixed cells on the glass slide after step 5. Scale bar, $10 \mu \mathrm{m}$. B. Fixed cells on the glass slide after step 10. Chlorophyll pigments are extracted and the color of the cells turn transparent. Scale bar, $10 \mu \mathrm{m}$. C. Differential interference contrast image of Chlamydomonas cell. Arrowhead indicates the pyrenoid structure where $\mathrm{CO}_{2}$-fixation enzyme Rubisco is enriched. 
Scale bar, $5 \mu \mathrm{m}$. D. Indirect immunofluorescence signals derived from anti LCIB-antibody. LCIB is detected as a ring-like structure around the pyrenoid as shown in the previous report (Yamano et al. 2010). Scale bar, $5 \mu \mathrm{m}$.

\section{$\underline{\text { Notes }}$}

We highly recommend that user also performs the same experiment using a target gene mutant as a negative control to distinguish true signals from artifact.

\section{Recipes}

1. $4 \%$ formaldehyde

a. Heat $80 \mathrm{ml}$ of PBS to approximately $60^{\circ} \mathrm{C}$ on a stir plate.

b. Add $4 \mathrm{~g}$ of paraformaldehyde and slowly raise the $\mathrm{pH}$ by adding $1 \mathrm{~N} \mathrm{NaOH}$ until the solution becomes clear.

c. After dissolving, cool and filter the solution.

d. Fill up the volume to $100 \mathrm{ml}$ with PBS and adjust the $\mathrm{pH}$ with diluted $\mathrm{HCl}$ to approximately 6.9 .

e. Aliquoted solutions can be kept at $-20^{\circ} \mathrm{C}$ for a month.

2. PBS

Dissolve $8 \mathrm{~g}$ of NaCl, $0.2 \mathrm{~g}$ of KCl, $1.44 \mathrm{~g}$ of $\mathrm{Na}_{2} \mathrm{HPO}_{4}$, and $0.24 \mathrm{~g}$ of $\mathrm{KH}_{2} \mathrm{PO}_{4}$ in $900 \mathrm{ml}$ of distilled $\mathrm{H}_{2} \mathrm{O}$. Adjust the $\mathrm{pH}$ to 7.4 with $\mathrm{HCl}$ and add $\mathrm{H}_{2} \mathrm{O}$ to $1 \mathrm{~L}$.

3. PBS-T

Add $0.1 \%$ Tween-20 (v/v) to PBS.

4. Blocking solution

$5 \%(w / v)$ globulin-free BSA in PBS buffer

\section{Acknowledgments}

We thank Lianyong Wang for technical assistance. This work was supported by the Japan Society for the Promotion of Science KAKENHI Grants 25120714 (to H.F.) and 25840109 (to T.Y.) and the Japan Science and Technology Agency Advanced Low Carbon Technology Research and Development Program.

\section{References}

1. Ohnishi, N., Mukherjee, B., Tsujikawa, T., Yanase, M., Nakano, H., Moroney, J. V. and Fukuzawa, H. (2010). Expression of a low CO(2)-inducible protein, LCl1, increases inorganic carbon uptake in the green alga Chlamydomonas reinhardtii. Plant Cell 22(9): 3105-3117. 
2. Shakes, D. C., Miller, D. M., 3rd and Nonet, M. L. (2012). Immunofluorescence microscopy. Methods Cell Biol 107: 35-66.

3. Yamano, T., Tsujikawa, T., Hatano, K., Ozawa, S., Takahashi, Y. and Fukuzawa, H. (2010). Light and low- $\mathrm{CO}_{2}$-dependent LCIB-LCIC complex localization in the chloroplast supports the carbon-concentrating mechanism in Chlamydomonas reinhardtii. Plant Cell Physiol 51(9): 14531468.

4. Yamano, T., Sato, E., Iguchi, H., Fukuda, Y. and Fukuzawa, H. (2015). Characterization of cooperative bicarbonate uptake into chloroplast stroma in the green alga Chlamydomonas reinhardtii. Proc Natl Acad Sci U S A 112(23): 7315-7320. 